\title{
Xenophobia: detrimental impacts on health care provision in developed countries
}

\section{Editorial}

A phobia is any irrational fear (DSM5), and when the fear is of anything that is different to oneself, or on a wider scale of any culture or people that is different to your own, this is known as xenophobia (www.merriam-webster.com). There are two major levels of detrimental impacts on health care provision that are attributable to xenophobia. First is the primary level, or direct impact of discrimination and prejudicial treatment of professional health care providers by the government agencies and administrative bodies who are mandated to oversee or monitor the registration or licensure of those professionals. Then there is the secondary level or indirect impact with the implications of not allowing those professionals with overseas qualifications and training to practice in the area in which they have been trained. Both of these areas are governed by international laws governing any developed country who is a member of the World Trade Organization (WTO), and member countries are governed by human rights under UNESCO for the practice of professional occupations as a basic human right.

The Tokyo, Bangkok, and Lisbon Conventions which have been signed by many developed countries who are members in the WTO guarantee two basic human rights regarding professional occupations such as those in health care: a) The right to qualifications being assessed correctly and acknowledgment of equivalency in levels of qualifications, and b) The right to practice the profession at a level afforded by the level of qualification obtained in the home country. For example, if someone who has a Bachelor's degree in Psychology from the United States goes to work in Australia, and the Australian Psychological Society (APS) assesses the qualification to be equivalent to a 5year undergraduate APAC degree in Australia, then the health professional would be required to do one year of supervised professional practice in the $5+1$ program in order to become a Registered Psychologist in Australia. This is comparable to the level of professional practice afforded by the qualification if that person where to apply for licensure in the United States. However, if that same person had also completed a 2year professional clinical placement as well as a 4year Master's degree in Psychology by coursework, assessed by the APS and AEI-NOOSR as equivalent to an APAC 4year course of study in Australia, then the person would not be expected to complete any supervised professional practice as they would have completed the minimum 6years required in graduate studies, including 2years of professional supervised practice in order to become fully licenced in the US, or the equivalent of full Registration and Clinical Endorsement in Australia.

The disturbing reality, however, is that health care professionals are not being allowed to practice in foreign countries due to incorrect assessment of their qualifications by these administrative organisations. Unfortunately employees with little or no experience working overseas, or training in assessment of overseas qualifications or professional practice, and no experience with international postgraduate qualifications in health care have been making decisions beyond their personal limitations, resulting in a distorted biased and prejudicial view towards those trained overseas. Thus,

\author{
Volume 4 Issue I - 2016
}

\author{
Nadira T Pardo \\ School of Behavioral Sciences, California Southern University, \\ USA
}

Correspondence: Nadira T Pardo, School of Behavioral Sciences, California Southern University, USA, Tel +6I 438606099, Email nadira.pardo@my.calsouthern.edu

Received: December 02, 2015 | Published: January II, 2016

xenophobia within the organisations is at the heart of the bias and prejudicial treatment against foreigners with overseas qualifications. As with most forms of prejudice, or irrational fears, the underlying cause is one of general ignorance about the cultures, customs, or professional practices in how the programs are administered, assessed or accredited, especially with supervised work placements required for licensure or registration. For example, one case, which the author is familiar with, has been going on for over 10years, with over 6years of appeals to the Australian Health Practitioner Regulation Agency, involves the case of a person with 14years of full-time APA (American Psychological Association) accredited qualifications in Psychology from a respected university in the USA. Although both the US and Australia are members of the WTO, and both are signatories to all three international conventions (Lisbon, Tokyo, and Bangkok) governing the equivalency of academic qualifications and professional practice they afford, this is one of many cases where xenophobic administrators lack the training, skills, or expertise to do their job properly. In fact, under UNESCO, the authority for assessment of overseas qualifications falls under AEI-NOOSR in Canberra ACT, a government agency specifically established to assess the equivalency of professional qualifications. However, AHPRA continues to ignore their advice as well as the advice of the APS in this particular case. The obvious question then is "to what end?"

Thus, damage to the overall public health is by way of negligence, resulting from refusing Registration of qualified health professionals based upon xenophobic prejudicial administrative practices. With a potential for seeing one client every 30 minutes, a conservative estimate with an average workload over the 10years this particular professional has been refused Registration amounts to 62,400 clients that have not received professional health care that his person could have provided in a very remote regional area that has no other practitioners. Currently there are severe shortages in health care professionals in Australia, especially in mental health, and in regional and remote areas, prompting a revision in the way services are delivered throughout the country in recent times. With such highly qualified and trained professionals willing to work in regional and remote locations, where there are no current practitioners, the 
xenophobes are having an extreme detrimental impact on health care provision in that country.

At a recent meeting of Professional Psychologists, 4 out of 5 had experienced issues of general ignorance or administrative oversights in their dealings with AHPRA, with one person taking a leave of absence to go on maternity leave and not being allowed to resume her supervised practice program upon return from her leave, but this is another type of discrimination, falling under the same category of human rights, which all member countries in the WTO have agreed to abide by.

Most professionals who have experienced the prejudicial and biased treatment have chosen to ignore it, making remarks to the effect that they had determined it was not worth the fight; however those who have chosen to fight for their human rights to practice the profession they have been trained to do, have met legal challenges including Machiavellian tactics of the highly paid legal professionals at the disposal of those government agencies, who have resorted to defamation presenting falsified reports and testimonies to the courts to get these cases dismissed on a routine basis. With many health care professionals exhausting all internal appeals available to them, turning to the Federal Ombudsman for help and getting none, then exhausting all avenues of external appeals, it is no wonder some cases are carrying on for over 10years. With limited resources due to these professionals having no way to work or get paid without Licensure or Registration in those countries, and without money to fund their legal appeals, the justice system is also failing to assist these individuals as the systems have been set up unconstitutionally in ways to send tenacious appellates around in circles.

In conclusion, failure to properly acknowledge academic qualifications from another country as well as the professional training and experience is a xenophobic practice that countries who are members of the WTO cannot afford to make, as it only hurts the people of that country who would otherwise have access to more health care professionals, many of whom have better qualifications and training compared to the average professionals in the countries they choose to make their new home. In Australia the culture has a phenomenon known as the "Tall Poppy Syndrome" which unfortunately is also prevalent in government agencies, tending to deliberately attack and ensure that people who have held high positions get trampled and treated like dirt. This author hasoverheard conversations of employees plotting the demise of health care professionals to "teach them a thing or two" about humility, even when the professional has only exhibited a high level of self-confidence, not perceived arrogance, as suggested by the remarks. When so many potential clients suffering from illnesses are not getting the treatment they deserve, can a culture allow such prejudice and xenophobic attitudes to override basic human rights? $?^{1,2}$

\section{Acknowledgements}

None.

\section{Conflict of interest}

The author declares no conflict of interest.

\section{References}

1. American Psychiatric Association. Diagnostic and statistical manual of the mental disorders. 5th ed. Washington DC, USA: DSM library; 2013.

2. http://www.merriam-webster.com/dictionary/xenophobia 